\title{
Orthophosphate Transport in the Erythrocyte of Normal Subjects and of Patients with X-Linked Hypophosphatemia
}

\author{
H. S. Tenenhouse and C. R. Scriver \\ From the DeBelle Laboratory for Biochemical Genetics, McGill University- \\ Montreal Children's Hospital, Research Institute, \\ Montreal, Quebec, Canada H3H 1 P3
}

A B S TRACT We have examined the mechanism of TCA-soluble orthophosphate $\left(P_{1}\right)$ transfer across the membrane of mature human erythrocytes in normal subjects and in patients with $\mathrm{X}$-linked hypophosphatemia (X-LH). The studies were carried out largely at $\mathrm{pH} 7.4$ and $37^{\circ} \mathrm{C}$, in partial simulation of conditions in vivo. (a) At physiological concentrations (1-2 $\mathrm{mM}$ ) $P$ i enters the intact normal erythrocyte down its chemical gradient and under no conditions could we identify a steady-state trans-membrane gradient for $P$, greater than 0.6. Calculations of the phosphate anion distribution ratio using the Nernst equation yield theoretical values that closely approximate observed values. (b) Glycolytic inhibitors have little effect on total entry of ${ }^{82} \mathrm{P}$ into erythrocytes but they do affect the intracellular distribution of $\mathrm{P}_{i}$. In the presence of iodoacetamide, label accumulates almost exclusively in the orthophosphate pool and less than $1 \%$ enters the organic phosphate pool. (c) Specific activity measurements in unblocked cells indicate that $\mathrm{P}_{\mathrm{r}}$ anion equilibrates first with its intracellular $P_{6}$ pool. These initial findings imply that neither group translocation, nor energy coupling, influence $P_{t}$ permeation into the human erythrocytes. $(d)$ The relationship between ${ }^{82} \mathrm{P}$ entry and extracellular $P$, concentration is parabolic in the presence of chloride, and linear in the presence of sulfate. The kinetics of concentration dependent entrance cannot be examined and saturability of $P_{c}$ entry cannot be identified under these conditions. (e) The competitive inhibitor arsenate partially inhibits the initial rate and steady-state flux of orthophosphate in erythrocytes treated with iodoacetamide to inhibit glycolysis. However, a significant portion of $P_{t}$ transport escapes ar-

Dr. Tenenhouse holds a postdoctoral fellowship from the Medical Research Council of Canada.

Received for publication 30 August 1973 and in revised form 11 October 1974. senate inhibition. $(f)$ Activation energies for $P_{1}$ entry, in nonglycolizing erythrocytes are much higher than those required by simple diffusion in an aqueous system. ( $g$ ) Neither the inward or outward movement of $\mathrm{P}_{\mathrm{i}}$ is modulated by trans-phosphate. These latter findings suggest that transport of phosphate across the human erythrocyte is compatible with slow facilitated diffusion with symmetry for influx and efflux.

The transmembrane chemical distribution ratio, and the equilibrium flux of $P$, were not different from normal in the X-LH erythrocyte. Nor did the extracellular $P_{\text {r concentration, arsenate, or temperature affect } P_{\text {}}}$ entry differently in the two types of cells. We deduce that different gene products serve the diffusional type of $P_{t}$ transport in the erythrocyte membrane and the saturable component of transepithelial absorption in the gut and kidney. Only the latter is affected by the $\mathrm{X}-\mathrm{LH}$ mutation. The former is apparently present not only in erythrocytes but also in epithelial tissue, where it can serve the absorption of pharmacologic amounts of $\mathrm{P}_{\mathrm{t}}$ in the therapeutic repair of the depleted phosphate pools in X-LH.

\section{INTRODUCTION}

X-linked hypophosphatemia $(\mathrm{X}-\mathrm{LH})^{1}$ has eluded unequivocal explanation for the mechanism of aberrant phosphate metabolism ever since the first description of this form of vitamin D-resistant rickets (1) almost $40 \mathrm{yr}$ ago. Recently, it has been proposed that the transport defect involves a component of net transtubular absorption of phosphate in kidney that is sensitive to PTH and calcium ions (2). The uptake of TCA-

\footnotetext{
${ }^{1}$ Abbreviations used in this paper: HEPES, N-2-hydroxyethylpiperazine- $N^{\prime}$-2-ethanesulfonic acid; $\mathrm{P}_{t}, \mathrm{P}_{o}$, and $\mathrm{P}_{t}$ are used to indicate, respectively, TCA-soluble orthophosphate, organic phosphate, and total phosphate pools in erythrocytes, or medium; X-LH, X-linked hypophosphatemia.
} 
soluble orthophosphate $\left(P_{1}\right)$ by intestinal mucosa in vitro may also be impaired (3) in some, but not all (4), probands with X-LH. These results lend support to the hypothesis that the phenotypic abnormality in $\mathrm{X}-\mathrm{LH}$ is a primary impairment of transepithelial $\mathrm{P}_{\mathrm{s}}$ transport in kidney and in other tissues (2).

It is of interest to know whether the mutant "transport" allele in X-LH is expressed also in nonepithelial cells. Moreover, since X-LH patients can absorb $\mathrm{P}$ ، from the intestine at high concentrations, and can restore their endogenous $P_{6}$ pools (5), we have tried to identify what type of $P_{1}$ transport serves this therapeutic response. We chose to examine the erythrocyte for this purpose, since changes in phosphate-dependent metabolism have been observed in that cell in X-LH (5). The evidence presented here indicates that phosphate is transported across the erythrocyte membrane by means of a carrier which permits symmetric facilitated diffusion. This mode of phosphate transport is not modified by the X-LH mutation. It follows that this carrier can accommodate the pharmacologic response to high concentrations of $\mathrm{P}_{\mathrm{r}}$ and that another mode of phosphate entry, which serves the physiologic needs of transepithelial absorption, is deficient in X-LH.

\section{METHODS}

\section{Procedures}

Preparation of cells. Erythrocytes were separated from freshly drawn blood by centrifugation at $3,000 \mathrm{~g}$ for $5 \mathrm{~min}$. The buffy coat was removed and the erythrocytes were washed three times and suspended in phosphate-free medium containing $120 \mathrm{mM} \mathrm{NaCl}, 5 \mathrm{mM} \mathrm{KCl}, 1 \mathrm{mM} \mathrm{MgCl}_{2}, 10$ $\mathrm{mM}$ D-glucose, and $20 \mathrm{mM}$ Tris- $\mathrm{HCl}$ at $\mathrm{pH}$ 7.4. N-2-hydroxy-ethylpiperazine- $N^{\prime}$-2-ethanesulfonic acid (HEPES) buffer was substituted for Tris- $\mathrm{HCl}$ in the experiments performed at $\mathrm{pH} 6.8$. Experiments were carried out at $37^{\circ} \mathrm{C}$ and at about $20 \%$ hematocrit in flasks placed in a Dubnoff shaking incubator. The number of erythrocytes per unit volume of initial reaction mixture was determined with a hemocytometer. Hemoglobin was analyzed using Drabkin's solution and measurement of absorbance at $540 \mathrm{~nm}$.

Incubation procedure for measurement of net uptake. After preliminary incubations of erythrocytes for $5 \mathrm{~min}$ at $37^{\circ} \mathrm{C}$, the reaction was initiated by the addition of ${ }^{32} \mathrm{P}$ (approximately $0.15 \mu \mathrm{Ci} / \mathrm{ml}$ incubation mixture). In all experiments stock solutions of sodium phosphate adjusted to $\mathrm{pH} 7.4$ (or $\mathrm{pH} 6.8$ ) were utilized. When the concentration of $\mathrm{P}_{4}$ in the medium was to be increased above 1.2 $\mathrm{mM}$, the appropriate amount of $\mathrm{NaCl}$ was removed to maintain osmolarity of the medium at 300 mosM. Aliquots $(1 \mathrm{ml})$ were withdrawn at appropriate times and processed according to the method of Kepner and Tosteson (6). Dibutylphthalate is used in this method to avoid the necessity of several washings to separate the erythrocytes from the ${ }^{22} \mathrm{P}$-containing extracellular medium.

Measurement of phosphate. The erythrocyte pellets were extracted with 3 vol of cold $10 \%$ trichloracetic acid; the $\mathrm{P}_{\mathrm{t}}$ in the extract was then separated from organic phosphate $\left(\mathrm{P}_{\mathrm{o}}\right)$ and analyzed both chemically and isotopically by the method of Vestergaard-Bogind (7). Total phosphate $\left(\mathrm{P}_{t}\right)$ in the extract was analyzed as described by Bartlett (8) and ${ }^{82} \mathrm{P}$ was counted in $10 \mathrm{ml}$ Aquasol with a liquid scintillation counter. The radioactivity, as well as the amount of phosphorus in $\mathrm{P}_{0}$ was obtained by subtracting the value for $\mathrm{P}_{t}$ from $\mathrm{P}_{t}$.

Phosphate in the high-energy pool in erythrocytes was determined by one of two methods $(9,10)$. First, by hydrolyzing an aliquot of the trichloracetic acid extract in $1 \mathrm{~N}$ sulfuric acid for $10 \mathrm{~min}$ at $100^{\circ} \mathrm{C} .{ }^{32} \mathrm{P}$, was then isolated as described above and counted. The difference between the values for hydrolyzed and nonhydrolyzed samples, indicates the so-called acid-labile fraction representing the "high-energy pool" of ADP and ATP (9). In the second method ${ }^{32} \mathrm{P}$ accumulation in the terminal phosphate of ADP and ATP was determined by the charcoal method described by Crane and Lipmann (10). Both methods yield similar results.

Uptake of $P_{1} ;$ variable trans-phosphate. Phosphate influx was examined in the presence of excess anion on the inner (trans) side of the erythrocyte membrane. Movement inward was examined as follows. Washed erythrocytes were incubated in $30 \mathrm{mM} \mathrm{P} \mathrm{P}_{i}$ for $15 \mathrm{~min}$ at $37^{\circ} \mathrm{C}$ to elevate the internal (trans) phosphate. The cells were then diluted with the $\mathrm{P}_{\mathbf{s}}$-free $\mathrm{pH} 7.4$ Tris-electrolyte buffer, centrifuged, and washed twice. The cells were then resuspended in a phosphate-free medium and the rate of ${ }^{32} \mathrm{P}$ entry into the phosphate-loaded cells was compared with the rate of entry into erythrocytes which had been preincubated in phosphate-free buffer and treated as described above. The second incubation was performed for $15 \mathrm{~min}$ at $37^{\circ} \mathrm{C}$ in the presence of cis-phosphate $(0.78 \mathrm{mM})$ and iodoacetamide to maintain intracellular ${ }^{32} \mathrm{P}$ in the $\mathrm{P}_{t}$ pool; the normal, low rate of entry remains linear in the initial

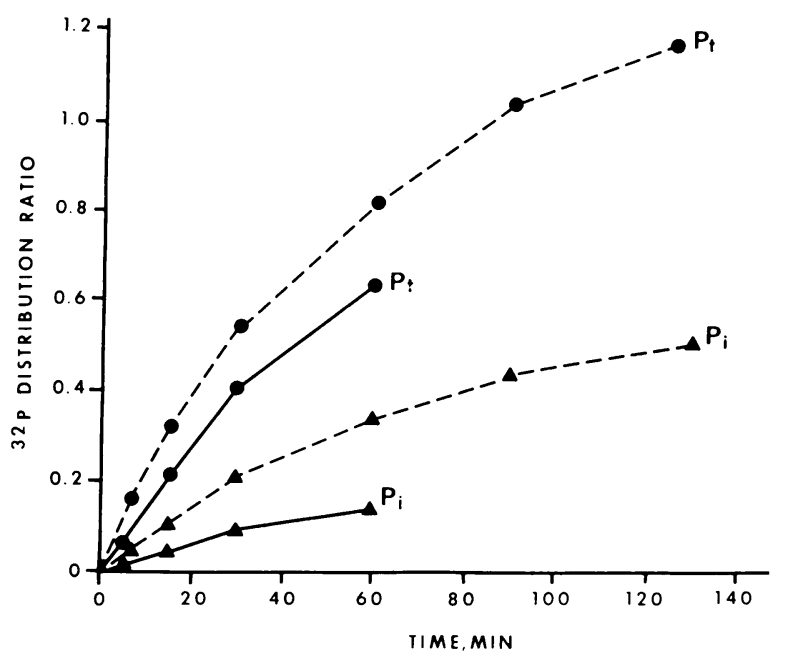

FIGURE 1 Time-courses for the entry of ${ }^{32} \mathrm{P}_{\mathfrak{i}}$ into the total (TCA-soluble) fraction of erythrocyte phosphate $\left(\mathrm{P}_{t}, \bullet\right)$ and into the orthophosphate pool $\left(\mathrm{P}_{i}, \boldsymbol{\Delta}\right)$. Incubations were carried out at $37^{\circ} \mathrm{C}$ in buffered medium at $\mathrm{pH} 7.4$ $(-)$ and $\mathrm{pH} 6.8(--)$ as described in Methods. The incubation medium was $1.2 \mathrm{mM}$ with respect to phosphate and had a specific activity of $200 \mathrm{cpm} / \mathrm{nmol}$. Uptake is expressed as an isotopic distribution ratio that is, ${ }^{32} \mathrm{P}$ counts/ minute per milliliter erythrocyte water: ${ }^{32} \mathrm{P}$ counts/minute per milliliter incubation medium. The intracellular water was assumed to be 0.72 of the erythrocyte volume (11).

Orthophosphate Transport in Erythrocytes 


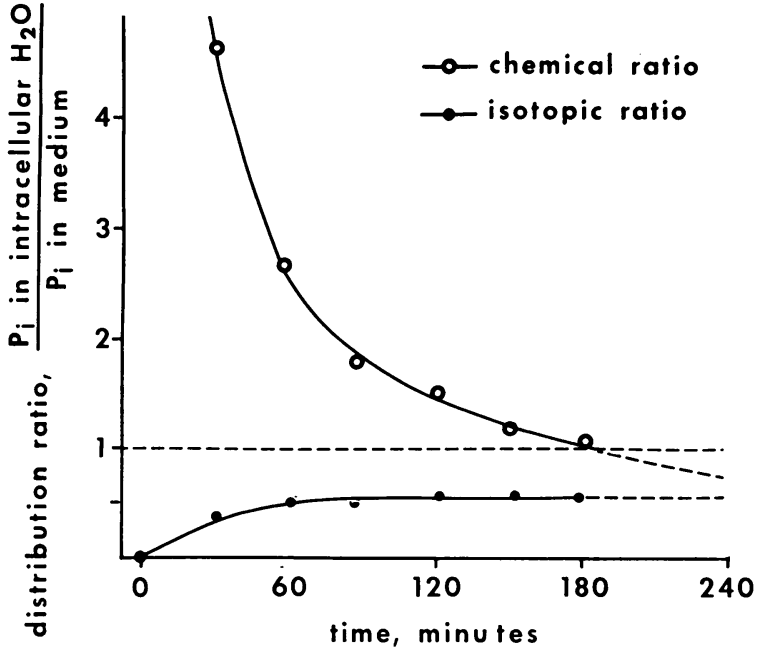

FIgURE 2 Time-courses for chemical (upper curve) and ${ }^{32} \mathrm{P}$ isotopic (lower curve) distribution ratios, when the zero-time concentrations of extracellular and intracellular $P_{\imath}$ in nonglycolizing iodoacetamide-treated normal human erythrocytes were 0.10 and $0.475 \mathrm{mM}$, respectively. The incubations were performed at $37^{\circ} \mathrm{C}, \mathrm{pH} 7.4$ at $20 \%$ hematocrit in Tris buffer.

$15 \mathrm{~min}$. Samples of medium and cells were analyzed both chemically and isotopically for phosphate to correct for back flux.

Efflux: none or trans-phosphate. Efflux of ${ }^{32} \mathrm{P}$ from erythrocytes was also examined. Cells were labeled with
${ }^{32} \mathrm{P}$ for $70 \mathrm{~min}$ at $37^{\circ} \mathrm{C}$ in the presence of $1 \mathrm{mM} \mathrm{P}_{\mathrm{i}}$ and $10 \mathrm{mM}$ iodoacetamide to contain the internal label in the $\mathrm{P}_{\text {i }}$ pool. Under these conditions, a steady-state was reached. The cells were then diluted 2.5 -fold with cold $\mathrm{P}_{4}$-free medium, centrifuged, and the erythrocyte pellet was washed twice with the same buffer. Efflux measurements were done at $20 \%$ hematocrit; efflux for $15 \mathrm{~min}$ at $37^{\circ} \mathrm{C}$ into a phosphate-free medium (no trans- $P_{\mathfrak{l}}$ ) containing $10 \mathrm{mM}$ iodoacetamide was compared with efflux into a medium in which the trans- $\mathrm{P}_{\text {، }}$ concentration was identical to that in the ${ }^{82} \mathrm{P}$ labeled erythrocytes. Samples of medium and cells were analyzed both chemically and isotopically for $\mathrm{P}_{4}$.

Equilibrium flux and effect of arsenate. Phosphate flux under conditions of steady-state exchange (influx equals efflux) was also investigated in the erythrocyte. It was determined that in the presence of 0.1 or $1.0 \mathrm{mM} \mathrm{P}$ and $10 \mathrm{mM}$ iodoacetamide, erythrocytes reached a steady-state after at least $1 \mathrm{~h}$ incubation at $37^{\circ} \mathrm{C}$. Experiments were thus performed by preincubating erythrocytes in $\mathrm{P}_{i}$ for 70 min, after which time ${ }^{32} \mathrm{P}$ was added to the medium. Aliquots of cells and medium were analyzed for phosphate by chemical and isotopic methods at zero time and after $15 \mathrm{~min}$ incubation. Net ${ }^{32} \mathrm{P}_{\imath}$ flux was ascertained from the distribution of label in external and internal pools. The effect of arsenate on the steady-state phosphate flux was studied by adding sodium arsenate at $\mathrm{pH} 7.4$ to the incubation mixture along with ${ }^{32} \mathrm{P}$.

Measurement of endogenous intracellular $P_{4}$. The concentration of intracellular inorganic phosphate was measured in the erythrocyte of normal and X-LH subjects. These studies were performed when X-LH patients had not received the oral phosphate supplement (5) for at least $48 \mathrm{~h}$. The cells in $1.0 \mathrm{ml}$ of freshly drawn blood were centrifuged through dibutylphthalate as described above.
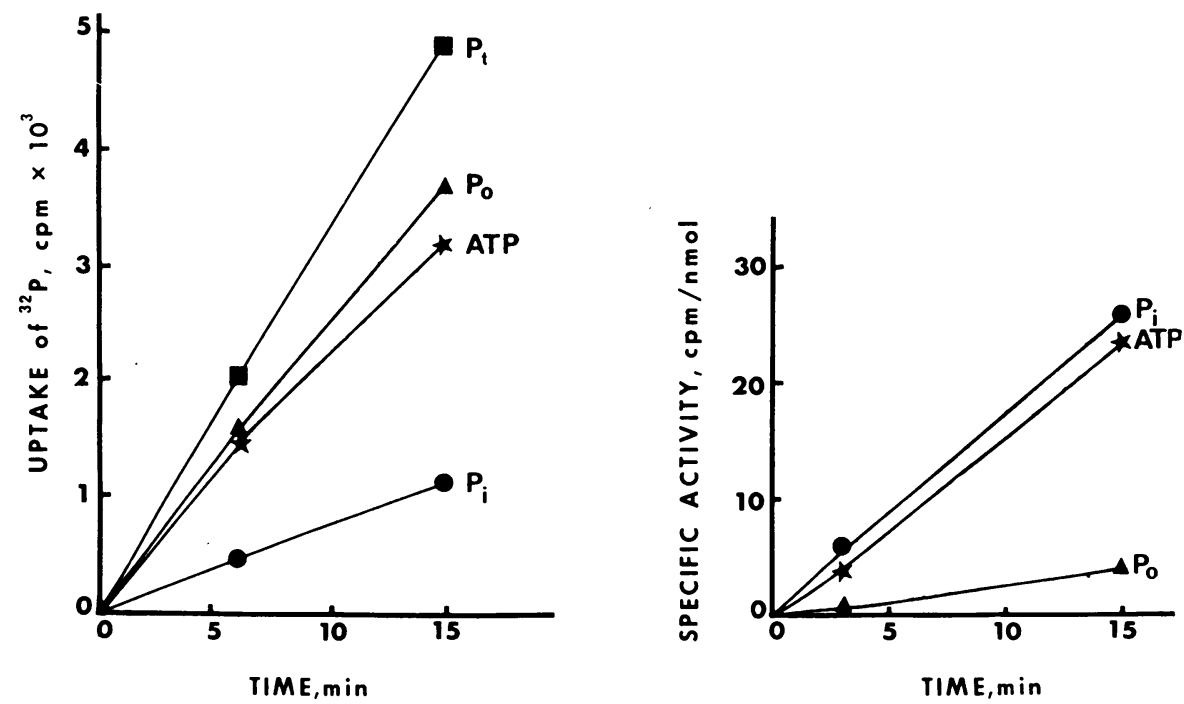

Figure 3 (A) Left. Time-course of ${ }^{22} \mathrm{P}$ entry into the total (TCA-soluble) fraction of erythrocyte phosphate $\left(\mathrm{P}_{t}, \boldsymbol{\square}\right)$, the organic phosphate pool $\left(\mathrm{P}_{o}, \boldsymbol{\Delta}\right)$, the inorganic phosphate pool $(\mathrm{P}, \bullet)$, and the "acid-labile" and/or "charcoal absorbable" high energy phosphate pool ("ATP," *). Uptake is standardized to cpm per $16.4 \mathrm{mg}$ hemoglobin. (B) Right. Graph showing the change in specific activity with time in the pools of inorganic phosphate $\left(P_{i}, \bullet\right)$, organic phosphate $\left(\mathrm{P}_{0}, \boldsymbol{\Delta}\right)$ and charcoal-absorbable, high energy phosphate ("ATP," *). Experiments were performed at $37^{\circ} \mathrm{C}, \mathrm{pH} 7.4$. The incubation medium, $1.2 \mathrm{mM}$ with respect to phosphate, had a specific activity of $440 \mathrm{cpm} / \mathrm{nmol}$. 
TABLE I

Effect of Inhibitors of Glycolysis on ${ }^{32} P$ Entry into Normal Human Erythrocyte Phosphate Pools

\begin{tabular}{cccc}
\hline & \multicolumn{3}{c}{$\%$ of control } \\
\cline { 2 - 4 } Treatment & Into $\mathrm{P}_{\boldsymbol{t}}$ & Into $\mathrm{P}_{\boldsymbol{i}}$ & Into $\mathrm{P}_{o^{*}}$ \\
\hline Sodium fluoride $(10 \mathrm{mM})$ & $104 \ddagger$ & $208 \S$ & 88 \\
2-deoxyglucose $(10 \mathrm{mM}) \|$ & $97 \ddagger$ & $295 \S$ & 56 \\
Iodoacetamide $(10 \mathrm{mM})$ & $118 ף$ & $655 \S$ & 18 \\
\hline
\end{tabular}

Incubations were carried out in $1.2 \mathrm{mM}$ phosphate for $15 \mathrm{~min}$ at $37^{\circ} \mathrm{C}$. No preincubation was carried out with sodium fluoride or iodoacetamide; erythrocytes were preincubated with 2-deoxyglucose for $1 \mathrm{~h}$ before addition of ${ }^{22} \mathrm{P}$. All determinations were at least in duplicate.

* Derived value obtained by subtracting uptake into $\mathrm{P}_{\boldsymbol{i}}$ pool from uptake into total phosphate $\left(\mathrm{P}_{t}\right)$.

$\ddagger$ Not significantly different from control by Student's $t$ test. $\S P<0.005$.

|| Incubation with 2-deoxyglucose was performed in the absence of D-glucose and the results were compared with controls incubated in the absence of $\mathrm{D}$-glucose.

If $P<0.05$

The erythrocyte pellet was then extracted with $3 \mathrm{vol}$ of cold trichloroacetic acid, and aliquots were then analyzed for $P_{4}$. All calculations of intracellular phosphate were based on a water content of the erythrocyte equal to 0.72 of the erythrocyte volume (11).

\section{Chemicals}

${ }^{32} \mathrm{P}(10 \mathrm{mCi} / \mathrm{mmol})$ and Aquasol were purchased from New England Nuclear, Boston, Mass. Trizma base and 2deoxyglucose were obtained from Sigma Chemical Co., St. Louis, Mo. HEPES was purchased from Calbiochem, San Diego, Calif. Iodoacetamide, dibutylphthalate, and all common chemicals were obtained from Fisher Scientific Co., Pittsburgh, $\mathrm{Pa}$. Iodoacetamide stock solutions $(1 \mathrm{M})$ in 0.1 $\mathrm{M}$ Tris buffer $\mathrm{pH} 7.4$ were prepared immediately before use.

\section{Patients}

Three hemizygous X-LH boys, one severely affected heterozygous girl, and four adult heterozygotes were studied. Blood was drawn in the morning after an overnight fast. Non-X-LH was used as a disease control. The control subjects were age and sex matched.

\section{RESULTS}

Time-course of phosphate entry into normal erythrocytes. The entry of $P_{1}(1.2 \mathrm{mM})$ into the $\mathrm{P}_{t}$ pool, and into the $\mathrm{P}_{i}$ pool of glycolyzing erythrocytes achieves a steady-state only after incubation in excess of 120 min (Fig. 1). $\mathrm{P}_{\mathrm{i}}$ enters erythrocytes at a linear rate during the first $15 \mathrm{~min}$ of incubation; all subsequent experiments were performed under comparable initialrate conditions. The $P_{i}$ distribution ratio (intracellu- lar counts in $P_{i}$ : extracellular counts in $P_{t}$ ) remained below 1.0 in glycolyzing cells.

Entry of ${ }^{32} \mathrm{P}$ into human erythrocytes is stimulated by lowering the ambient $\mathrm{pH}$ from 7.4 to 6.8 (Fig. 1). $18 \%$ of total intracellular ${ }^{32} \mathrm{P}$ is in the $\mathrm{P}$ pool at $\mathrm{pH}$ 7.4 after $15 \mathrm{~min}$, whereas the corresponding fraction is $40 \%$ at $\mathrm{pH}$ 6.8. All subsequent studies were performed at $\mathrm{pH} 7.4$.

We also examined the kinetics of ${ }^{32} \mathrm{P}$-labeled $\mathrm{P}_{\mathrm{s}}$ entry into nonglycolyzing cells when the initial external $P_{i}$ concentration was $0.12 \mathrm{mM}$, the initial internal erythrocyte $\mathrm{P}_{\mathrm{t}}$ was $0.8 \mathrm{mM}$, and the cell was exposed to iodoacetamide $(10 \mathrm{mM})$; the latter permits less than $1 \%$ of the permeant ${ }^{32} \mathrm{P}$ to enter the $\mathrm{P}_{o}$ pool (see below). Chemical and isotopic distribution ratios were then calculated; the former fell with time while the latter rose, both approaching a distribution ratio of 0.6 approximately after prolonged incubation (Fig. 2). The latter observation indicates that the anion is not concentrated against a chemical gradient in the erythrocyte.

We examined whether the observed steady-state $P_{i}$ distribution ratio was different from that expected at normal resting transmembrane potential under conditions of Donnan equilibrium. We assumed that the monovalent phosphate anion distribution ratio in the nonglycolyzing cell is comparable to the chloride distribution ratio (approximately 0.7 ). We then calculated the divalent phosphate anion ratio (the square of the

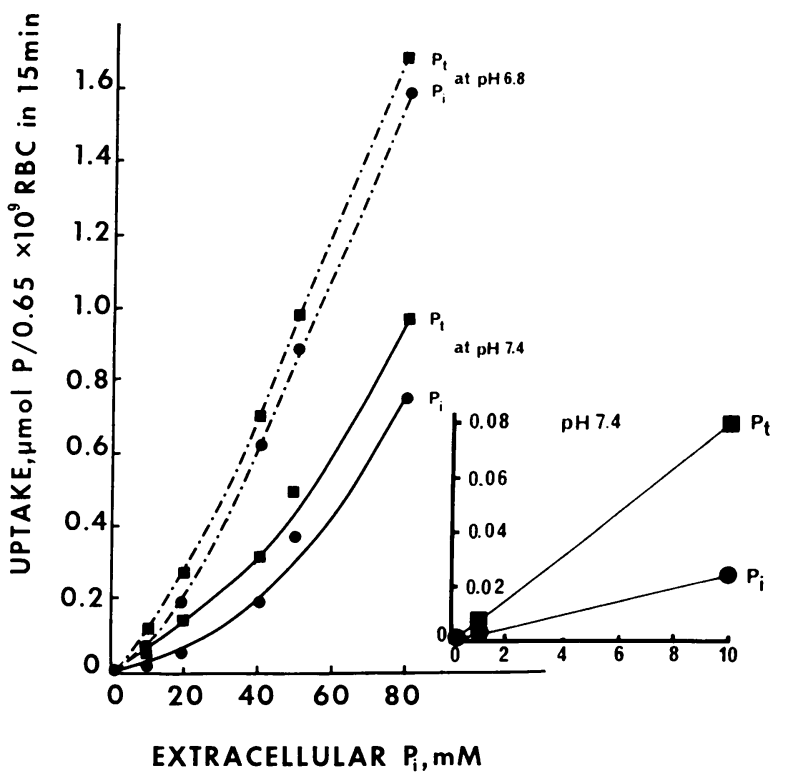

Figure 4 The effect of extracellular $P_{i}$ concentration on the entry of ${ }^{32} \mathrm{P}$ into the total TCA-soluble fraction of erythrocytes $\left(\mathrm{P}_{t}, \square\right)$ and into the inorganic phosphate pool $\left(\mathrm{P}_{\mathrm{l}}, \bullet\right)$. 15-min incubations were carried out at $\mathrm{pH} 7.4$ $(\longrightarrow)$ and $\mathrm{pH} 6.8(--)$ as described in Methods.

Orthophosphate Transport in Erythrocytes 
TABLE II

Effect of Arsenate and Sulfate on Net Entry of ${ }^{32} P$ into Normal Human Erythrocytes

\begin{tabular}{|c|c|c|c|}
\hline \multirow[b]{2}{*}{ Treatment } & \multicolumn{3}{|c|}{$\%$ of control } \\
\hline & Into $P_{t}$ & Into $P_{i}$ & Into $\mathrm{P}_{o}$ * \\
\hline Arsenate $(5 \mathrm{mM})$ & $68 \ddagger$ & $160 \ddagger$ & 33 \\
\hline $\begin{array}{l}\text { Arsenate }(5 \mathrm{mM}) \\
\quad \text { iodoacetamide }(10 \mathrm{mM}) \S\end{array}$ & $69 \ddagger$ & $63 \ddagger$ & $\|$ \\
\hline $\begin{array}{l}\text { Sulfate }(5 \mathrm{mM}) \\
\quad \text { iodoacetamide }(10 \mathrm{mM}) \S\end{array}$ & 1079 & 98 ศ & $\|$ \\
\hline
\end{tabular}

Incubations were carried out in $0.1 \mathrm{mM}$ phosphate for $15 \mathrm{~min}$ at $37^{\circ} \mathrm{C}$ in $\mathrm{pH} 7.4$ buffer. All determinations were at least in duplicate.

* Derived value, obtained by subtracting uptake into $\mathrm{P}_{i}$ pool from uptake into $\mathrm{P}_{\imath}$ pool.

$\ddagger P<0.005$ by Student's $t$ test.

$\S$ Erythrocytes were preincubated in $10 \mathrm{mM}$ iodoacetamide for $5 \mathrm{~min}$ at $37^{\circ} \mathrm{C}$ before the addition of the appropriate anion. II In the presence of iodoacetamide, but without additional anion in the medium, $<1 \%$ of the initial ${ }^{32} \mathrm{P}$ counts in erythrocytes are in the $\mathrm{P}_{o}$ pool.

I Difference from control not significant.

monovalent ion ratio), and thereby calculated the ratio for the combined phosphate anion species at extracellular $\mathrm{pH} 7.4$ when the ratio of $\mathrm{PO}_{4}{ }^{=}: \mathrm{PO}_{4}^{-}$is $81: 19$. We also assumed that activity coefficients and dissocia-

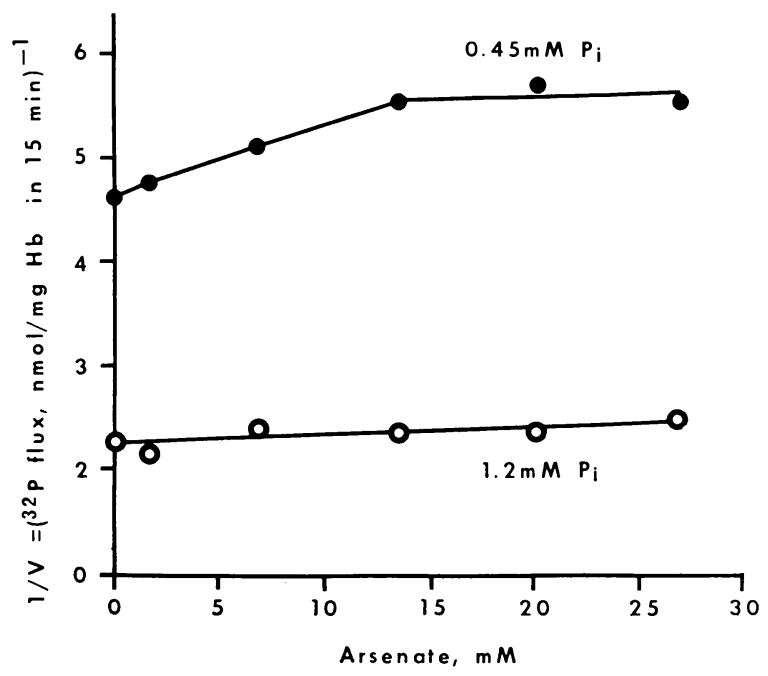

FIGURE 5 The effect of arsenate on the entry of $P_{i}$ under steady-state conditions. (Rate of influx equals rate of efflux.) The graph indicates that arsenate is a competitive inhibitor of $\mathrm{P}_{1}$ transfer. However, the maximum inhibition does not exceed $20 \%$ and a significant fraction of $\mathrm{P}_{t}$ flux at physiological concentration apparently escapes inhibition by arsenate. $P_{t}$ concentration in medium is indicated on the graph. tion constants for phosphate are similar inside and outside the erythrocyte. The distribution ratio, thus calculated, is 0.53 and is similar to the observed value. Moreover, back calculation with the appropriate Henderson-Hasselbalch equation for phosphate yields a theoretical intracellular $\mathrm{pH}$ of 7.24. Therefore, we deduce that the $\mathrm{P}_{\mathrm{r}}$ distribution ratio observes Donnan equilibrium.

We then examined ${ }^{32} \mathrm{P}$ incorporation into various phosphate fractions in erythrocytes (Fig. $3 a$ ). The high-energy phosphate pool, for simplicity referred to as the "ATP pool," is labeled more rapidly than the $P$ ، pool. At $15 \mathrm{~min}$ approximately $90 \%$ of the counts incorporated into $\mathrm{P}_{0}$ are accounted for by ATP.

Time-courses for the specific activity of intracellular $P_{i}, P_{o}$, and ATP reveal that the $P_{i}$ pool is more heavily labeled than the ATP pool during initial uptake (Fig. $3 b$ ) while both are more heavily labeled than the $\mathrm{P}_{0}$ pool. The findings suggest that $\mathrm{P}_{\mathrm{i}}$ does not participate in group translocation (12) during its passage across the erythrocyte membrane.

Effect of glycolytic inhibitions on $P_{i}$ entry into normal erythrocytes. The effect of various glycolytic inhibitors (sodium fluoride, iodoacetamide, and 2-deoxyglucose) was examined to determine whether glycolysis influences ${ }^{32} \mathrm{P}$ entry. Erythrocytes were preincu-

TABLE III

Effect of Trans-Phosphate on Unidirectional Flux of ${ }^{32} \mathrm{Pi}$ in Normal Human Erythrocytes*

\begin{tabular}{|c|c|c|c|c|}
\hline \multirow{2}{*}{$\begin{array}{l}\text { Direction } \\
\text { of flux } \\
\text { measured } \ddagger\end{array}$} & \multicolumn{2}{|c|}{$\begin{array}{c}\text { Concentration } \\
\text { of } P_{i}\end{array}$} & \multicolumn{2}{|c|}{$P_{i}$ Flux rate } \\
\hline & Cis & Trans & In original state & With trans $P_{i}$ \\
\hline & \multicolumn{2}{|c|}{$m M$} & \multicolumn{2}{|c|}{$n m o l P_{i} m g ~ H b^{-1}, 15 \mathrm{~min}^{-1} \S$} \\
\hline \multirow[t]{2}{*}{ Inward } & 0.78 & 0.63 & \multirow[t]{2}{*}{$0.345 \pm 0.005$} & \\
\hline & 0.78 & 5.55 & & $0.340 \pm 0.005 \|$ \\
\hline \multirow[t]{2}{*}{ Outward } & 1.65 & 0.005 & \multirow[t]{2}{*}{$0.623 \pm 0.003$} & \\
\hline & 1.65 & 1.78 & & $0.654 \pm(0.006)$ \\
\hline
\end{tabular}

Data are the average of measurements in duplicate.

* All experiments were performed at $\mathrm{pH} 7.4,37^{\circ} \mathrm{C}$ with cells exposed to iodoacetamide $(10 \mathrm{mM}) ;<1 \%$ of ${ }^{32} \mathrm{P}$ escapes from $\mathrm{P}_{i}$ pool under these conditions. Dilution of specific activity in extracellular medium by unlabeled $P_{i}$ effluxing from cells was accounted for in all experiments.

$\ddagger$ Inward flux was measured by adding cells prepared with internal (trans) $\mathrm{P}_{i}$ as indicated in third column, to ${ }^{32} \mathrm{P}$-labeled external (cis) medium of composition as indicated in second column. Outward flux was determined by adding preincubated and labeled cells with internal (cis) $P_{i}$ content to incubation medium of defined trans composition.

$\S \mathrm{P}_{i}$ flux rates are linear with time during initial $15 \mathrm{~min}$ in either direction.

\| Not significantly different from control by Student's $t$ test. 


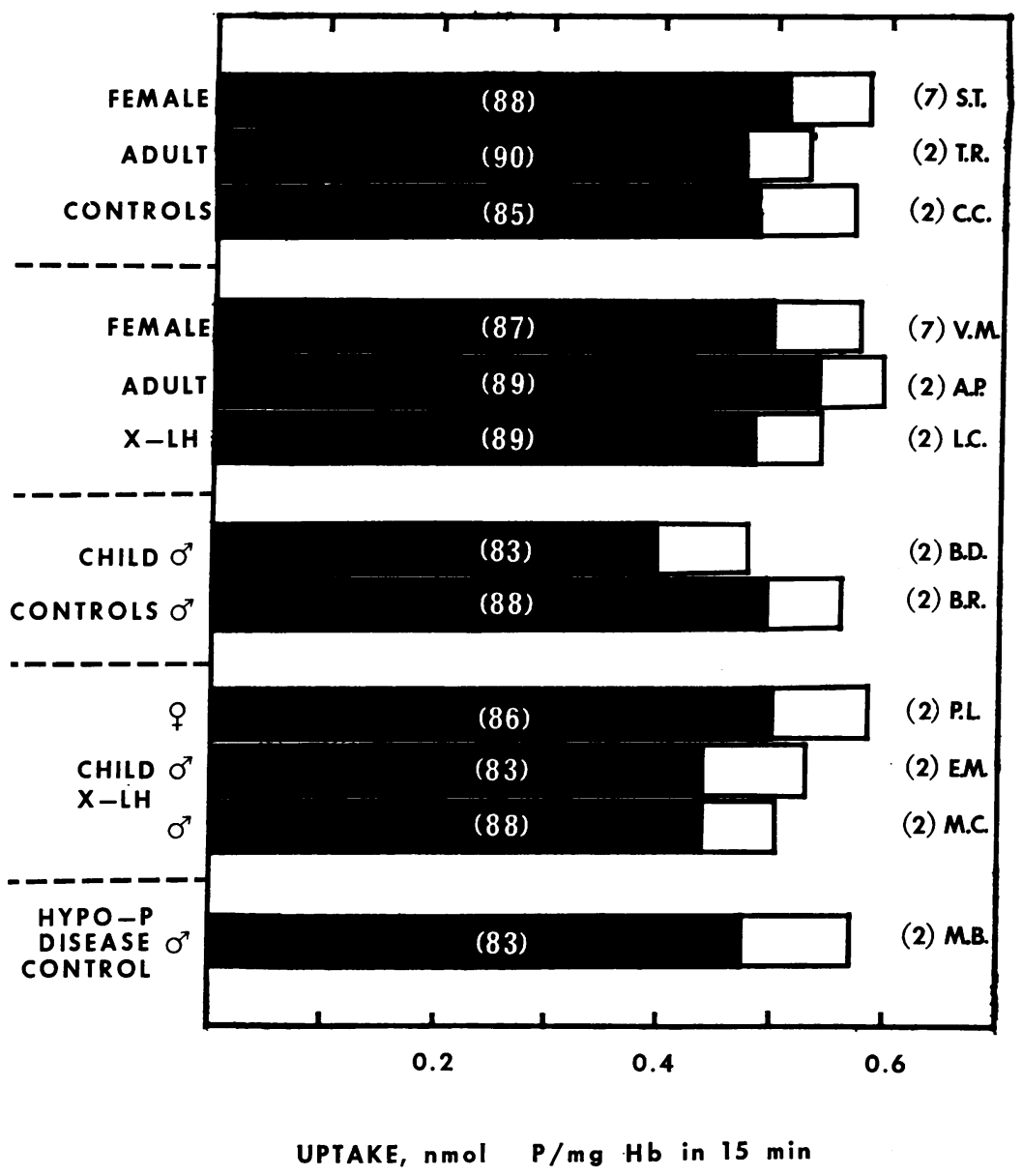

FIGURE 6 Entry of external ${ }^{2} \mathrm{P}$ into the inorganic ( $\square$ ) and organic ( $\square$ ) phosphate pools in TCA-soluble extracts of erythrocytes obtained from 5 normal subjects ( S. T., T. R., C. C., B. D., and B. R.), 6 patients with X-linked hypophosphatemia (V. M., A. P., L. C., P. L., E. M., and M. C.) and one non-X-LH control (M. B.). The black numbers in parenthesis represent the number of determinations performed on each individual. The white numbers in parenthesis in the shaded portion of the columns represent the percent of total ${ }^{20} \mathrm{P}$ entry found in the inorganic phosphate pool at 15 min. Incubations were performed in $\mathrm{pH} 7.4$ buffer for $15 \mathrm{~min}$ at $37^{\circ} \mathrm{C}$ in the presence of $10 \mathrm{mM}$ iodoacetamide and $1 \mathrm{mM}$ orthophosphate. Absence of preincubation in iodoacetamide accounts for higher incorporation of ${ }^{20} \mathrm{P}$ into $\mathrm{P}$.

bated with 2-deoxyglucose for $1 \mathrm{~h}$ to allow depletion of endogenous substrates in the presence of this particular agent. Iodoacetamide is the best inhibitor of glycolysis under the conditions studied (Table I). In each case, the glycolytic inhibitor affects the distribution of intracellular ${ }^{\circledR 2} \mathrm{P}$. It decreases the entry of ${ }^{22} \mathrm{P}$ into $\mathrm{P}_{0}$ and diminishes the specific activity of the latter, whereas entry into the $P$, pool increases and the specific activity of this fraction of intracellular phosphate is augmented. Neither sodium fluoride nor 2-deoxyglucose has any effect on the entry of total ${ }^{*} \mathrm{P}$, whereas iodoacetamide produces a slight but reproducible stimulation of total ${ }^{*} \mathrm{P}$ entry, perhaps through an effect on $\mathrm{Na} / \mathrm{K}$ gradients and Donnan equilibrium.
Relationship between concentration and entry of phosphate into erythrocytes. The effect of extracellular solute concentration on the rate of phosphate entry into erythrocytes is shown in Fig. 4. The relationship of entry to concentration of $\mathrm{P}_{\mathrm{t}}$ conforms to an inverted parabola at $\mathrm{pH} 6.8$ and $\mathrm{pH}$ 7.4. Replacement of $\mathrm{Cl}^{-}$by sulfate produced a linear relationship between $\mathrm{P}_{\mathrm{i}}$ entry rate and its extracellular concentration. The latter finding confirms an earlier observation (13), and indicates that the kinetics of concentration dependence cannot be examined under the conditions of our experiments.

Interaction between phosphate and arsenate or sulfate during entry into erythrocytes. Arsenate is a com- 
TABLE IV

Equilibrium Flux of Phosphate in the Original State and in the Presence of Arsenate in Normal and $X-L H$ Erythrocytes

\begin{tabular}{|c|c|c|c|}
\hline \multirow{2}{*}{$\begin{array}{c}\text { Subject } \\
\text { phenotype }\end{array}$} & \multicolumn{2}{|c|}{ Steady-state flux } & \multirow{2}{*}{$\begin{array}{c}\text { Inhibition } \\
\text { by } \\
\text { arsenate }\end{array}$} \\
\hline & Control & $13 \mathrm{mM}$ arsenate & \\
\hline & \multicolumn{2}{|c|}{$n m o l ~ P_{i} m g ~ H b^{-1} 15 m i n^{-1}$} & $\%$ \\
\hline Normal female & $0.175 \pm 0.003$ & $0.144 \pm 0.003$ & 18 \\
\hline X-LH female & $0.190 \pm 0.002$ & $0.153 \pm 0.003$ & 20 \\
\hline $\mathrm{X}$-LH male & $0.179 \pm 0.003$ & $0.144 \pm 0.003$ & 20 \\
\hline
\end{tabular}

The three samples of washed erythrocytes were incubated simultaneously at $37^{\circ} \mathrm{C}$ in the presence of $0.12 \mathrm{mM} \mathrm{P} i$ and $10 \mathrm{~m} \mathrm{M}$ iodoacetamide for $70 \mathrm{~min} .{ }^{32} \mathrm{P}$ was then added, in the presence or absence of arsenate, to the mixture and incubation was allowed to proceed for 15 additional min. Each value represents the mean of two determinations.

Student's $t$ test reveals no significant difference between the three genotypes for steady-state flux of $\mathrm{P}_{i}$ or for the response to arsenate.

petitive inhibitor of phosphate transport both in bacteria (14) and in Ehrlich ascites carcinoma cells (15). We examined the effect of arsenate on phosphate entry into erythrocytes. A 50 -fold excess of arsenate $(5 \mathrm{mM}$ arsenate vs. $0.1 \mathrm{mM}$ phosphate) causes a significant decrease in the entry of ${ }^{32} \mathrm{P}$ into $\mathrm{P}_{t}$ and $\mathrm{P}_{0}$ (Table II). Under these conditions the fraction of ${ }^{32} \mathrm{P}$ retained as $P_{\imath}$ is increased. Arsenate competes with $P_{\imath}$ for interaction with D-glyceraldehyde-3-phosphate dehydrogenase, thereby inhibiting the formation of 1,3-diphosphoglyceric acid. In the presence of arsenate, 1-arseno3 -phosphoglyceric acid is formed; the latter is unstable in water and undergoes rapid hydrolysis to 3-phosphoglyceric acid and arsenate. Therefore, it is difficult to interpret the effect of arsenate on phosphate entry in erythrocytes which sustain active glycolysis. Erythrocytes were pretreated with iodoacetamide to dissociate the metabolic effects from the effect of arsenate on

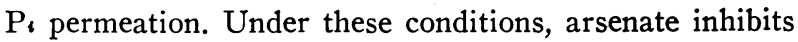
the net entry of ${ }^{32} \mathrm{P}$ into the $\mathrm{P}_{\mathrm{i}}$ pool by $37 \%$ (Table II). Sulfate, in the presence of iodoacetamide, does not inhibit phosphate entry into human erythrocytes (Table II).

We further examined the interaction between arsenate and phosphate in the iodoacetamide-treated cell, under equilibrium conditions, when the unidirectional fluxes of $\mathrm{P}_{i}$ inward and outward are equal. Arsenate inhibits influx of phosphate up to $20 \%$ at low concentrations of substrate. A Dixon plot of the interaction between arsenate and $P_{c}$ (Fig. 5) indicates competitive inhibition. No further inhibition is observed at the low $P_{\imath}$ concentration when the molar ratio of arsenate: $P_{\text {s }}$ exceeds $30: 1$. The finding suggests that only a fraction of $P_{t}$ transport is arsenate sensitive and that another part of the permeation may involve a mechanism that escapes interaction with arsenate.

Effect of temperature on phosphate entry in normal erythrocytes. Although phosphate entry is not dependent on glycolysis in normal erythrocytes (Table I), the initial rate of $P_{t}$ entry is nonetheless sensitive to temperature. The $Q_{10}$ for rates of $P_{1}$ entry between $27^{\circ} \mathrm{C}$ and $37^{\circ} \mathrm{C}$ lies between 4.0 and 5.0 even in the presence of iodoacetamide (see below, Table V).

Cis-trans test for a phosphate anion carrier. Further evidence for a phosphate anion carrier in the erythrocyte was sought by examining the effect of the transphosphate concentration on its inward movement. Phosphate entry was measured at $0.78 \mathrm{mM}$, that is, at a concentration similar to the intracellular $\mathrm{P}$, concentration of the "unloaded" erythrocytes and compared with the rate of entry into erythrocytes which had been filled with $\mathrm{P}_{\mathrm{i}}$ during preincubation to an internal concentration in excess of $5 \mathrm{mM}$. Entry is not stimulated by prior loading of cells with trans-phosphate (Table III). A correction was made for the dilution of extracellular specific activity by efflux from $\mathrm{P}_{\imath}$-loaded cells.

We also examined the influence of trans-phosphate on the outward flux. Efflux experiments allowed us to observe clearly the difference between trans-zero and trans-phosphate on net flux. Erythrocytes were preincubated with labeled $P_{t}$ to establish $1.65 \mathrm{mM} \mathrm{P}_{\mathfrak{t}}$, in the presence of iodoacetamide to maintain ${ }^{32} \mathrm{P}$ predominantly in the $P_{\imath}$ pool. Efflux was measured in the initial 15 min after washing the cells and transferring them into medium containing iodoacetamide and no phosphate or trans-phosphate at $1.78 \mathrm{mM}$. The rate of ${ }^{82} \mathrm{P}$ ،

\begin{tabular}{lcc}
\multicolumn{3}{c}{ TABLE V } \\
Effect of Temperature on $\begin{array}{c}{ }^{32} P \text { Entry } \\
\text { and } X \text {-LH Erythrocytes }\end{array}$ \\
\hline \multicolumn{1}{c}{ Phenotype } & $\begin{array}{c}Q_{10} \text { of control } \\
\text { cells* }\end{array}$ & $\begin{array}{c}Q_{10} \text { of iodoacetamide } \\
\text { treated cells } \neq\end{array}$ \\
\hline Control female & 5.3 & 4.4 \\
X-LH female & 5.2 & 4.4 \\
X-LH male & 4.7 & 4.5 \\
\hline
\end{tabular}

Conditions as described in Table I. Experiments done in duplicate, at least.

* Ratio of entry rate during initial $15 \mathrm{~min}$ at $37^{\circ} \mathrm{C}$ to that observed at $27^{\circ} \mathrm{C}$.

$\ddagger$ Erythrocytes were preincubated for $5 \mathrm{~min}$ at $37^{\circ} \mathrm{C}$ in $10 \mathrm{mM}$ iodoacetamide before addition of ${ }^{32} \mathrm{P}$ and unlabeled $\mathrm{P}_{i}$ (final concentration, $1.2 \mathrm{mM}$ ). Under these conditions, less than $1 \%$ of total ${ }^{32} \mathrm{P}$ counts appears in the $\mathrm{P}_{o}$ pool after entry. 
efflux is identical in the presence and absence of transphosphate (Table III).

These studies lead us to believe that phosphate permeation in the erythrocyte is largely accommodated by symmetric facilitated diffusion. We then examined $\mathrm{X}$ $\mathrm{LH}$ cells to determine whether this mediation is impaired by the mutation.

Phosphate entry into $X-L H$ erythrocytes. No difference in $\mathrm{P}_{\mathrm{s}}$ entry was observed between normal and $\mathrm{X}-\mathrm{LH}$ cells under the standard conditions of incubation (1.2 mM extracellular $P_{\imath}, 15 \mathrm{~min}$ incubation at $37^{\circ} \mathrm{C}, \mathrm{pH} 7.4$ in Tris- $\mathrm{HCl}$ medium). When entry was measured in the presence of iodoacetamide $(10 \mathrm{mM})$, no significant difference was again observed between normal and X-LH cells (Fig. 6). Concentration-dependent entry of $P_{i}$ over the range $1-60 \mathrm{mM}$ was also similar in normal and X-LH erythrocytes. The inward flux of phosphate at $0.12 \mathrm{mM}$ under equilibrium conditions in iodoacetamide-treated cells was similar in X-LH and normal cells (Table IV). Arsenate impairs $P$. flux to the same degree in the two types of erythrocytes (Table IV). Initial rates of $P_{i}$ entry observed similar $Q_{10}$ values in normal and X-LH cells (Table V).

The in vivo erythrocyte chemical distribution ratio for $P_{\imath}$ (intraerythrocyte $P_{i}$ : serum $P_{\imath}$ ) remains constant at about 0.5 , at $\mathrm{P}_{\mathbf{r}}$ concentrations in serum between $0.6 \mathrm{mM}$ and $1.8 \mathrm{mM}$ in the normal and the $\mathrm{X}$-LH phenotypes (Fig. 7). This finding indicates that the mutant gene in X-LH does not directly perturb the $P_{t}$ distribution ratio across the erythrocyte membrane; any changes in erythrocyte metabolism in X-LH will thus correlate with the $\mathrm{P}_{\boldsymbol{t}}$ concentration in serum.

\section{DISCUSSION}

The mode of phosphate entry into erythrocytes at concentrations corresponding to those in normal serum (1-2 $\mathrm{mM}$ ) has long been a matter of conjecture (16). For many years, it was thought that this process was closely associated with glycolysis; however, later evidence clearly contradicted that view (17). The results of our own investigations, for example, indicate that inhibitors of glycolysis have little or no effect on the penetration of the erythrocyte membrane by phosphate. In the presence of such inhibitors, there is indeed redistribution from the organic into the orthophosphate pool of erythrocytes, but total net entry remains essentially independent of the intracellular metabolism of phosphate. Therefore, energy coupling plays no role in phosphate entry into the erythrocyte; these features have been used to advantage in some of our investigations of that cell.

The use of dibutylphthalate (16) in our experiments has eliminated the need for several washings to sepa-

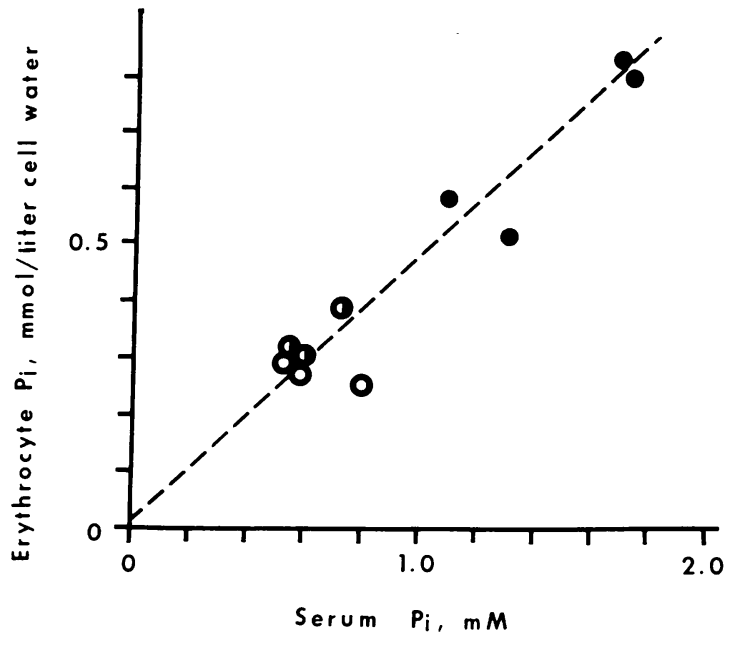

FIGURE 7 Relationship between intracellular and extracellular orthophosphate in normal adults and children (๑), heterozygotes for the X-LH gene (O) and mutant hemizygotes $(O)$. The data reveal that the chemical distribution ratio in vivo is approximately 0.5 in all genotypes. Each point is the mean of three determinations.

rate the erythrocyte from ${ }^{32} \mathrm{P}$-containing extracellular medium, thus avoiding substantial losses of intracellular orthophosphate while allowing a more accurate estimate of ${ }^{32} \mathrm{P}$ labeling of the various phosphate pools in erythrocytes. With this procedure we were able to show that isotopic and chemical distribution ratios for ${ }^{32} \mathrm{P}$ and $\mathrm{P}_{\mathrm{t}}$ between erythrocyte water and the extracellular medium, were both about 0.6 under in vitro conditions (Fig. 2). The distribution ratio in vitro is similar to the steady-state chemical distribution ratio observed in vivo in the present study and elsewhere $(18,19)$. The observed values correspond closely to the Donnan equilibrium for phosphate which we have calculated for the combined monovalent and divalent species of phosphate anion. We conclude that in the presence of the normal trans-membrane potential difference, phosphate must enter the erythrocyte down its chemical gradient. In this context the erythrocyte transports phosphate quite differently from kidney cortex, for example, where net $P_{i}$ transport occurs against a chemical gradient (unpublished data).

The specific activity of the intracellular orthophosphate pool is initially higher than the specific activity of the organic phosphate pools that we examined. In the presence of glycolytic inhibitors, the findings suggest that extracellular orthophosphate equilibrates directly with its intracellular pool and does not participate in group translocation (12) or flux through an organic pool as a necessary transition during permeation. Chedru and Cartier (20) have also studied the entry of $\mathrm{P}_{t}$ and the specific labeling of its intracellular

Orthophosphate Transport in Erythrocytes 
pools in erythrocytes. They performed their observations during the initial $30 \mathrm{~s}$ of entry and determined that the $\mathrm{P}_{i}$ pool is the precursor of the organic pool in human erythrocytes.

The absence of classical saturation kinetics for $P$, entry into human erythrocytes over the concentration range $0.30 \mathrm{mM}$ and $100 \mathrm{mM}$, has been observed in at least three other laboratories $(20-22)$ in addition to our own. The observation is valid under several conditions of extracellular $\mathrm{pH}$. Our own studies reveal the familiar inverted parabola (21) that characterizes $P_{i}$ entry over this broad range of concentration. Whereas cooperative interaction of the anion with a two-site model would be a fashionable interpretation for the behaviour of $\mathrm{P}_{\mathrm{i}}$ entry, it is recognized that phosphate anion is elevated in such experiments at the expense of chloride in the medium. The latter inhibits phosphate transport (13) and, therefore, the apparent acceleration of $\mathrm{P}_{\mathfrak{r}}$ uptake at high concentrations presumably reflects replacement of $\mathrm{Cl}^{-}$under these conditions. We also find that when sulfate is substituted for chloride in the incubation medium, a linear, rather than a parabolic relationship exists between $P_{i}$ uptake and concentration (13). However, when entry of an anion is modulated by other anions in the medium, it is difficult to make any claims about whether saturation of permeation is achieved or not (23). Our observations, therefore, do not rule out the presence of a carrier for

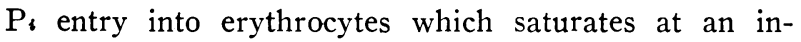
determinant concentration of anion.

We have searched further for the presence of a phosphate carrier by examination of $P_{\imath}$ transfer across the erythrocyte membrane at equilibrium, when the rate of influx equals that of efflux, and under conditions when manipulation of the $P_{1}$ concentration on the opposite (trans) side of the membrane can be used to inform about diffusion-like mechanisms. Trans-phosphate did not modify the flux rate of $\mathrm{P}_{\mathrm{t}}$ in either the inward or outward direction in our experiments. This finding indicates that the phosphate anion carrier, if it exists in the human erythrocyte membrane, participates only in a symmetric mechanism of facilitative diffusion.

In order to identify whether a phosphate carrier actually exists in the erythrocyte membrane, it was necessary to examine the interaction of arsenate and sulfate with the initial transfer of $P_{\mathfrak{t}}$, and on its flux under equilibrium conditions in the nonglycolizing erythrocyte. As predicted from the observations of Gruber and Deuticke (24), sulfate ( $5 \mathrm{mM}$ ) has no effect on phosphate entry under our standard conditions of incubation. On the other hand, sulfate can stimulate phosphate uptake by erythrocytes from a medium containing $10 \mathrm{mM}$ phosphate and approximately $102 \mathrm{mM}$ sulfate (24). The discrepancy between these two ob- servations is no doubt due to the difference in the conditions of incubation. The latter positive observation is important since it points to the existence of a carrier capable of interaction with both species of anion.

Arsenate causes a modest reduction of ${ }^{32} \mathrm{P}$ movement across the human erythrocyte membrane and the kinetics of this interaction in our experiments indicate competitive inhibition. Our studies were carried out in nonglycolyzing cells, in contrast to earlier comparable experiments (20) thus eliminating any artefact related to the effect of arsenate on phosphate metabolism. On the other hand, we observed that a portion of $\mathrm{P}_{\imath}$ permeation still escapes interaction with arsenate when the inhibitor: substrate ratio exceeds $30: 1$. This finding implies that more than one form of entry may characterize phosphate permeation in the human erythrocyte.

Gruber and Deuticke (24) have reported high activation energies per $\mathrm{P}_{i}$ permeation into glycolyzing erythrocytes. In our studies thermal coefficients exceeding 4.0 were observed in the presence of iodoacetamide, when less than $1 \%$ of $P_{i}$ enters enzyme-dependent organic pools. From this evidence, we conclude that the apparent high activation energy for $\mathrm{P}$. permeation, equivalent to about $27-30 \mathrm{~kg}-\mathrm{cal} / \mathrm{mol}$, reflects a temperature-sensitive event that occurs during membrane transfer and not during intracellular incorporation. This observation is again compatible with a membrane carrier serving facilitative diffusion. Comparable high activation energies have also been reported for the entry of sulfate ion (25) and of monovalent ions (26). Both types of ion have carriers for transfer across the membrane and yet they do not participate significantly in cellular metabolism in the glycolyzing erythrocyte.

The last part of our investigation was directed to an examination of phosphate transport in erythrocytes obtained from patients with X-LH. Under a variety of conditions, we examined flux rates, temperature dependence, concentration dependence, and interaction with arsenate. Under all conditions, $P_{i}$ transfer across the erythrocyte membrane was similar in X-LH patients and in normal subjects. However, phosphate pools in the erythrocyte are significantly depleted in hypophosphatemic X-LH patients (19) and under such conditions the relative rates of $P_{t}$ entry have been reported to be greater than normal in the glycolyzing $\mathrm{X}-\mathrm{LH}$ erythrocyte (19). We were careful to carry out our studies in the presence of iodoacetamide so that entry into the intracellular orthophosphate pool alone would be compared in control subjects and in patients. Our findings lead us to conclude that the defect in transepithelial transport of phosphate, which is evident in the kidney and in the intestine of patients with X-LH, 
is not present in their erythrocytes. We believe this is so because the saturable carrier, which serves an important component of transepithelial absorption, is not present in the erythrocyte membrane. The failure of genes, which instruct important membrane events in the transepithelial absorption of nutrients, to be expressed in nonepithelial tissues, is not a new observation. The most recent examples are found in the fibroblast studies of Groth and Rosenberg (27) and in the erythrocyte studies of Gardner and Levy (28). The former found normal uptake of dibasic amino acids and tryptophan in the cultured skin fibroblasts from patients with Hartnup disease and cystinuria in whom there was unequivocal evidence for impaired intestinal and renal tubular absorption of the relevant amino acids. The latter investigators found no defect in dibasic amino acid transport in cystinuric erythrocytes.

Our present erythrocyte data are nonetheless pertinent to at least two earlier observations in X-LH. First, the whole-blood partial-pressure of oxygen at $50 \%$ saturation $\left(\mathrm{P}_{50}\right)$ is low in the $\mathrm{X}-\mathrm{LH}$ patient with marked hypophosphatemia (5). Secondly, the concentrations of 2,3-diphosphoglycerate and total organic phosphate are diminished in the erythrocytes in children with hereditary hypophosphatemic states (19). Oral administration of phosphate in doses sufficient to raise the phosphate concentration in serum above $1 \mathrm{mM}$, restores $\mathrm{P}_{50}$ to normal in $\mathrm{X}-\mathrm{LH}$ subjects (5). Our present findings indicate that phosphate will be transported into X-LH erythrocytes by at least one arsenatesensitive diffusional mechanism, and perhaps by an arsenate-insensitive mechanism as well, and that the normal $P_{1}$ distribution ratio will be maintained. Intracellular $\mathrm{P}_{\mathrm{i}}$ concentration can thus be restored to normal in X-LH. Since dietary phosphate supplementation can accomplish this restoration in $\mathrm{X}-\mathrm{LH}$, it follows that comparable diffusional modes of $\mathrm{P}$ transport exist in epithelial tissues. The diffusional systems are not affected by the X-LH mutation and they permit adaptation in the absence of the saturable, concentrative mode of transport in absorptive epithelium in the $\mathrm{X}-\mathrm{LH}$ phenotype.

\section{ACKNOWLEDGMENTS}

We are most grateful to Terry Reade for her help with our studies in the X-LH patients. Dr. Ron Poole gave valuable assistance in calculating the phosphate distribution ratio from the Nernst equation. Mrs. Huguette Ishmael and Miss Lynne Prevost were patient and forebearing in the trials of preparing a manuscript for The Journal of Clinical Investigation.

The investigation was supported in part by grants from the Medical Research Council of Canada to the Medical Genetics Group at McGill University, and from the Quebec Network of Genetic Medicine.

\section{REFERENCES}

1. Albright, F., A. M. Butler, and E. Bloomberg. 1937. Rickets resistant to vitamin D therapy. Am. J. Dis. Child. 54: 529-547.

2. Glorieux, F., and C. R. Scriver. 1972. Loss of a parathyroid hormone-sensitive component of phosphate transport in X-linked hypophosphatemia. Science (Wash. D. C.). 175: $997-1,000$.

3. Short, E. M., H. J. Binder, and L. E. Rosenberg. 1973. Familial hypophosphatemic rickets: defective transport of inorganic phosphate by intestinal mucosa. Science (Wash. D. C.). 179: 700-702.

4. Glorieux, F. H., R. Travers, E. E. Delvin, C. L. Morin, and R. Poirier. 1974. Intestinal phosphate transport in familial hypophosphatemia. Pediatr. Res. 8: 381. (Abstr.)

5. Glorieux, F. H., C. R. Scriver, T. M. Reade, H. Goldman, and A. Roseborough. 1972. Use of phosphate and vitamin $\mathrm{D}$ to prevent dwarfism and rickets in X-linked hypophosphatemia. N. Engl. J. Med. 287: 481487.

6. Kepner, G. R., and D. C. Tosteson. 1972. Incubation of $\mathrm{HK}$ and $\mathrm{LK}$ sheep red cells in vitro for long periods. Biochim. Biophys. Acta. 266: 471-483.

7. Vestergaard-Bogind, B. 1964. Determination on a micro scale of concentration and specific radioactivity of inorganic phosphate ions in whole blood and packed red cells. Scand. J. Clin. Lab. Invest. 16: 457-464.

8. Bartlett, G. R. 1959. Phosphorus assay in column chromatography. J. Biol. Chem. 234: 466-468.

9. Latzkovits, L., I. Szentistvanyi, and C. S. Fajszi. 1972. Tracer kinetic analysis of phosphate incorporation into erythrocytes in vitro. I. A simple model for simultaneous investigation of phosphate transport and exchange in erythrocytes. Acta Biochim Biophys. Acad. Sci. Hung. 7: 55-66.

10. Crane, R. K., and F. Lipmann. 1953. The effect of arsenate on aerobic phosphorylation. J. Biol. Chem. 201 : 235-243.

11. Dittner, D. S., editor. 1961. Biological Handbooks. Blood and Other Body Fluids. Federation of American Societies for Experimental Biology. Washington, D. C. 19.

12. Christensen, H. N. 1960. Reactive sites and biological transport. Adv. Protein Chem. 15: 239-314.

13. Deuticke, B. 1967. Uber die Kinetik der PhosphatPermeation in den Menschen-Erythrocyten bei Variaton von Extracellulärer Phosphat-Konzentration, AnionenMilieu und Zell-Volumen. Pfluegers Archiv. Gesamte Physiol. Menschen Tiere. 296: 21-38.

14. Rosenberg, H., N. Medveczky, and J. M. La Nauze. 1969. Phosphate transport in Bacillus cereus. Biochim. Biophys. Acta. 193: 159-167.

15. Levinson, C. 1972. Phosphate transport in Ehrlich ascites tumor cells and the effect of arsenate. J. Cell. Physiol. 79: 73-78.

16. Garrahan, P. J. 1970. Ion movements in red blood cells. In Membrane and Ion Transport. E. E. Bittar, editor. John Wiley and Sons, Inc., New York. 2: 185-227

17. Zipursky, A., and L. G. Israels. 1961. Transport of phosphate into the erythrocyte. Nature (Lond.). 189: 1013-1015.

18. Bartlett, G. R. 1959. Human red cell glycolytic intermediates. J. Biol. Chem. 234: 449-458.

19. Cartier, P., J. P. Leroux, S. Balsan, and P. Royer. 1970. Etude de la glycolyse et de la perméabilité des érythrocytes aux ions orthophosphates dans le rachitisme vita-

Orthophosphate Transport in Erythrocytes

653 
mino-résistant hypophosphatémique héréditaire. Clin. Chim. Acta. 29 : 261-271.

20. Chedru, J., and P. Cartier. 1966. La perméabilité des globules rouges humaines aux ions orthophosphates. Biochim. Biophys. Acta. 126: 500-512.

21. Deuticke, B. 1970. Anion permeability of the red blood cell. Naturwissenschaften. 57: 172-179.

22. Vestergaard-Bogind, B. 1963. The transport of phosphate ions across the human red cell membrane. II. The influence of the concentration of inorganic phosphate on the kinetics of the uptake of $\left[{ }^{32} \mathrm{P}\right]$ phosphate ions. Biochim. Biophys. Acta. 66: 93-109.

23. Gunn, R. B., M. Dalmark, D. C. Tosteson, and J. O. Wieth. 1973. Characteristics of chloride transport in human red blood cells. J. Gen. Physiol. 61: 185-206.

24. Gruber, W., and B. Deuticke. 1973. Comparative as- pects of phosphate transfer across mammalian erythrocyte membranes. J. Membr. Biol. 13: 19-36.

25. Schnell, K. F. 1972. On the mechanism of inhibition of the sulfate transfer across the human erythrocyte membrane. Biochim. Biophys. Acta. 282: 265-276.

26. Dalmark, M., and J. O. Wieth. 1972. Temperature dependence of chloride, bromide, iodide, thiocyanate, and salicylate transport in human red cells. J. Physiol. (Lond.). 224: 583-610.

27. Groth, U., and L. E. Rosenberg. 1972. Transport of dibasic amino acids, cystine, and tryptophan by cultured human fibroblasts: absence of a defect in cystinuria and Hartnup disease. J. Clin. Invest. 51: 2130-2142.

28. Gardner, J. D., and A. G. Levy. 1972. Transport of dibasic amino acids by human erythrocytes. Metab. (Clin. Exp.). 21: 413-431. 